\title{
Spatial and Temporal Variability of Key Bio- Temperature Indicators and their Effects on Vegetation Dynamics in the Great Lakes Region of Central Asia
}

\section{Xuan Gao}

Institute of Geographic Sciences and Natural Resources Research

Dongsheng Zhao ( $\sim$ zhaods@igsnrr.ac.cn )

Institute of Geographic Sciences and Natural Resources Research

Lei Liu

Institute of Geographic Sciences and Natural Resources Research

\section{Research Article}

Keywords: Climate change, Normalized Difference Vegetation Index, bio-temperature, Great Lakes Region of Central Asia

Posted Date: January 17th, 2022

DOI: https://doi.org/10.21203/rs.3.rs-1234661/v1

License: (c) (1) This work is licensed under a Creative Commons Attribution 4.0 International License.

Read Full License 


\section{Abstract}

Dryland ecosystems are fragile to climate change due to harsh environmental condition. Climate change affects vegetation growth primarily by altering some key bio-temperature thresholds. Key biotemperatures are closely related to vegetation growth, and slight changes could produce substantial effects on ecosystem structure and function. Therefore, this study selected the number of days with daily mean temperature above $0{ }^{\circ} \mathrm{C}\left(\mathrm{DT}_{0}\right), 5^{\circ} \mathrm{C}\left(\mathrm{DT}_{5}\right), 10^{\circ} \mathrm{C}\left(\mathrm{DT}_{10}\right), 20^{\circ} \mathrm{C}\left(\mathrm{DT}_{20}\right)$, the start of growing season (SGS), the end of growing season (EGS), and the length of growing season (LGS) as bio-temperature indicators to analyze the response of vegetation dynamics to climate change in the Great Lakes Region of Central Asia (GLRCA) for the period 1982-2014. On the regional scale, $\mathrm{DT}_{0}, \mathrm{DT}_{5}, \mathrm{DT}_{10}$, and $\mathrm{DT}_{20}$ exhibited an overall increasing trend. Spatially, most of the study area showed that the negative correlation between $\mathrm{DT}_{0}, \mathrm{DT}_{5}, \mathrm{DT}_{10}, \mathrm{DT}_{20}$ with annual $\mathrm{NDVI}$ increased with increasing bio-temperature thresholds. Especially, more than $88.3 \%$ of the study area showed a negative correlation between annual $\mathrm{NDVI}$ and $\mathrm{DT}_{20}$, as increased $\mathrm{DT}_{20}$ exacerbated ecosystem drought. Moreover, SGS exhibited insignificantly advanced trend, and EGS experienced a significantly delayed trend. The overall extending trend in LGS was mainly attributed to the delayed EGS. Besides, our study revealed that about $54.7 \%$ of the study area showed a negative correlation between annual NDVI and LGS, especially in the north, indicating a negative effect of climate warming on vegetation growth in the drylands. The results of this study will help assess the stability of vegetation to climate variability, and predict the response of vegetation to future climate change in the GLRCA.

\section{Introduction}

Global surface temperature was $1.09^{\circ} \mathrm{C}$ higher in $2011-2020$ than $1850-1900$, with larger increases over land $\left(1.59^{\circ} \mathrm{C}\right)$ than over the ocean $\left(0.88^{\circ} \mathrm{C}\right)($ IPCC 2021$)$. Climate change characterized by global warming has a greater impact on the structure and function of terrestrial ecosystems (Cheng et al. 2021; Holst et al. 2013). Climate warming has intensified glacier melting and permafrost degradation (Bolch et al. 2010; Zheng et al. 2020), resulting in a series of ecological and environmental effects, such as the release of large amounts of deep permafrost carbon and declining water table (Wang et al. 2020). Meanwhile, climate warming enhanced vegetation productivity by promoting photosynthesis, extending growing seasons, especially at high latitudes and altitudes (Piao et al. 2007; Wang et al. 2011; Wei et al. 2018). In addition, plenty of evidence suggests that extreme high temperature events are increased with enhancement of frequency and intensity across the globe (Perkins et al. 2012; Tong et al. 2019). Although climate warming reduces the occurrence of extreme low temperature events, such as frost events, but the extension of the plant growing season due to warming may induce more frequent frost days during the growing season (Baumbach et al. 2017; Liu et al. 2018). Accompanied by changes in temperature, the adaptive capacity of vegetation to environmental changes and ecosystem vulnerability increases, significantly affecting the provision of global ecosystem services (Fu et al. 2013). Therefore, monitoring vegetation growth and understanding its response to temperature change is important for quantifying 
global carbon budget, and has become a hot topic in climate change research (Ballantyne et al. 2012; Sitch et al. 2015).

Ecosystems in arid and semi-arid regions are more fragile to climate change due to harsh environmental condition, and even slight changes in the climate can have a substantial influence on such ecosystems (Li et al. 2021a; Yuan et al. 2021). However, previous studies on climate change have mainly focused on the analysis of statistical distributions of climate variables, such as mean, maximum, and minimum values, while neglecting their association with ecosystems (Franzke 2015; Jiang et al. 2017). Climate change affects vegetation growth primarily by altering some key bio-temperature thresholds, such as $0^{\circ} \mathrm{C}$, $5^{\circ} \mathrm{C}, 10^{\circ} \mathrm{C}$, and $20^{\circ} \mathrm{C}$ (Yang et al. 2019; Yin et al. 2017; Zhao and Wu 2016). These temperature indicators are closely related to the growth and distribution of vegetation, and its changes may lead to alteration in ecosystem structure and function (Dong et al. 2012; Qiu and Lu 1980; Xiao et al. 2020). Recent evidence has indicated that changes in bio-temperature thresholds altered vegetation productivity and modified vegetation seasonality by affecting the initiation, termination and performance of vegetation photosynthetic activity over the Northern Hemisphere land (Xu et al. 2013). Meanwhile, the Normalized Difference Vegetation Index (NDVI), as a typical remote sensing index for measuring the vegetation greenness, was widely used to characterize the response of vegetation growth to climate change (Jiang et al. 2017; Piao et al. 2011; Wang et al. 2011). In recent decades, numerous studies have indicated that variations in global temperature have greatly affected vegetation dynamics in drylands (Luo et al. 2020; Yao et al. 2018). Nevertheless, few studies were focused on the relationship between key bio-temperature thresholds and NDVI. A quantitative assessment of the effects of changes in key bio-temperature thresholds on NDVI will helpful for understanding the response mechanisms of dryland ecosystems to climate change.

The Great Lakes Region of Central Asia (GLRCA) is located hinterland of the Eurasian continent, far from the ocean, and covers five countries: Kazakhstan, Kyrgyzstan, Turkmenistan, Tajikistan, and Uzbekistan, which is the largest dryland area in the temperate zone of the Northern Hemisphere (Li et al. 2015a; Yao et al. 2017). Over the past 33 years, the GLRCA has experienced rapid warming of approximately $0.36^{\circ} \mathrm{C}-$ $0.42^{\circ} \mathrm{C}$, which was stronger than the global average temperature (Hu et al. 2014). Greater warming significantly affects the intensity and frequency of extreme temperatures in the GLRCA, with an overall trend of increased extreme high temperature events and decreased extreme low temperature events (Liu et al. 2021; Luo et al. 2020; Zhang et al. 2019). Arid and semi-arid regions are very sensitive to climate change due to their fragile ecosystems and limited resilience to climate change (Lioubimtseva and Henebry 2009). Temperature changes can be directly reflected in changes in vegetation growth (Luo et al. 2020; Wu et al. 2021). Zhou et al. (2015) found that the warming trend in the GLRCA initially enhanced the greenness of vegetation before 1991, but then the continued warming trend inhibited further increase in greenness. In addition, several studies have also demonstrated that the increase in temperature prolonged the growing season, and in turn increased ecosystem productivity in some areas of the GLRCA (Bohovic et al. 2016; Wu et al. 2021). However, it remained uncertain how key bio-temperature thresholds changed over the GLRCA, and different bio-temperature may induce various impacts on terrestrial 
ecosystems under global warming. Therefore, it is essential to explore the spatial and temporal associations of vegetation growth and key bio-temperature thresholds in the GLRCA.

In this study, we selected the number of days with daily mean temperature above $0^{\circ} \mathrm{C}\left(\mathrm{DT}_{0}\right), 5^{\circ} \mathrm{C}\left(\mathrm{DT}_{5}\right)$, $10^{\circ} \mathrm{C}\left(\mathrm{DT}_{10}\right), 20^{\circ} \mathrm{C}\left(\mathrm{DT}_{20}\right)$, the start of growing season (SGS), the end of growing season (EGS), and the length of growing season (LGS) as key indicators of bioclimatology. Based on these indicators, we firstly investigated the temporal and spatial trends of bio-temperature in the GLRCA during the period 19822014. Secondly, Pearson's correlation coefficient was used to explore the correlation between NDVI and bio-temperature indicators, thus detecting the response of vegetation growth to temperature changes. This study provides a scientific basis for quantitative assessment of vegetation growth changes in dryland ecosystems under global warming, and will be helpful for decision-making in implementing ecological restoration and conservation in arid and semi-arid regions.

\section{Data And Methods}

\subsection{Data}

\subsubsection{NDVI data}

Remote sensing data, characterized by time continuity and large spatial scales, is an efficient approach to monitor the growth status and cover of vegetation (Goward 1989), and has been widely used in vegetation response to climate change studies (Li et al. 2015b; Wu et al. 2021). In this study, we used the Global Inventory Monitoring and Modeling Studies (GIMMS) NDVI dataset from 1982 to 2014 at a spatial resolution of $8 \mathrm{~km} \times 8 \mathrm{~km}$ and a bimonthly time resolution. This dataset is corrected through a series of processing steps to reduce noise interference from volcanic eruptions and sensor-induced errors, with high quality. To characterize the yearly growth of vegetation, we used the maximum value composite (MVC) method to obtain the monthly NDVI dataset, and yearly NDVI was defined as the average monthly composite NDVI (Piao et al. 2011; Wang et al. 2011).

\subsubsection{Climate data}

The daily mean temperature data used in this study was obtained from the GLDAS-2.0 dataset provided by the Global Land Data Assimilation System (GLDAS), covering our study period (1982-2014), with a spatial resolution of $0.25^{\circ} \times 0.25^{\circ}$. GLDAS combines simulation models with observations to provide long-term gridded meteorological datasets on a global scale, and has been widely used in climate change research (Ji et al. 2015; Wang et al. 2019; Zhong et al. 2011). Additionally, Ji et al. (2015) compared the GLDAS dataset with the Global Historical Climatology Network (GHCN) datasets (including 13511 weather stations), and found that the daily mean temperature data of GLDAS had a fairly high accuracy.

\subsection{Methods}

\subsubsection{Bio-temperature indicators}


Bio-temperature thresholds are closely related to the growth and distribution of vegetation, and $0^{\circ} \mathrm{C}, 5^{\circ} \mathrm{C}$, $10^{\circ} \mathrm{C}, 20^{\circ} \mathrm{C}$ have been widely used to assess regional heat resources (Yang et al. 2019; Yin et al. 2017; Zhao and $\mathrm{Wu}$ 2016). $5^{\circ} \mathrm{C}$ is the minimum temperature for photosynthesis of some tropical and subtropical evergreen broadleaf forests (Larcher and Biederman-Thorson 1980). Meanwhile, $5^{\circ} \mathrm{C}$ was often employed to quantify growing season length and was also considered to be a key indicator in modelling of global vegetation patterns in previous studies (Prentice et al. 1992; Ruml et al. 2017). Most thermophilic crops begin to grow when the daily mean temperature is steadily above $10^{\circ} \mathrm{C}$, and $\mathrm{DT}_{10}$ is closely associated with sprouting and withering of most arboreal leaves (Huang 1958; Qiu and Lu 1980). Furthermore, the number of days below $0^{\circ} \mathrm{C}$ (frost days) and $\mathrm{DT}_{20}$ are commonly used to characterize the variability of extreme temperature events (Sillmann et al. 2013; Xiao et al. 2020). To reduce the effect of extreme values, we employed a 6-day moving average as the daily mean temperature to calculate $\mathrm{DT}_{0}$, $\mathrm{DT}_{5}, \mathrm{DT}_{10}$ and $\mathrm{DT}_{20}$ in this study.

The effect of surface air temperature on vegetation growth is usually assessed by changes in the thermal growing season (Dong et al. 2012; Yin et al. 2019). Considering the heat requirements for most vegetation growth, the Expert Team on Climate Change Detection and Indices (ETCCDI) defined a set of growing season indicators based on daily mean temperature, and has been widely used in climate change studies (Cornes et al. 2019; Ruml et al. 2017). In the Northern Hemisphere, SGS was defined as the first day of the first 6-day period before July 1 st with a daily mean temperature greater than $5^{\circ} \mathrm{C}$, and EGS was determined as the first day of the first 6-day period after July 1 st with a daily mean temperature less than $5^{\circ} \mathrm{C}$. LGS was the number of days between SGS and EGS. Ultimately, seven bio-temperature indicators were selected in this study to analyze the effect of temperature change on vegetation growth across the GLRCA (Table 1).

Table 1

The bio-temperature indicators used in this study.

\begin{tabular}{|lll|}
\hline Label & Index Name & Unit \\
\hline $\mathrm{DT}_{0}$ & Number of days with $T_{\text {mean }}>0^{\circ} \mathrm{C}$ & Days \\
\hline $\mathrm{DT}_{5}$ & Number of days with $T_{\text {mean }}>5^{\circ} \mathrm{C}$ & Days \\
\hline $\mathrm{DT}_{10}$ & Number of days with $T_{\text {mean }}>10^{\circ} \mathrm{C}$ & Days \\
\hline $\mathrm{DT}_{20}$ & Number of days with $T_{\text {mean }}>20^{\circ} \mathrm{C}$ & Days \\
\hline $\mathrm{SGS}$ & Start of growing season & Julian days \\
\hline EGS & End of growing season & Julian days \\
\hline LGS & Length of growing season & Days \\
\hline
\end{tabular}

\subsubsection{Correlation analysis}


To examine the response of vegetation dynamics to temperature changes, we analyzed correlations between annual NDVI and various bio-temperature indicators using Pearson's correlation coefficient based on pixels (Wu et al. 2021).

$$
r=\frac{\sum_{i=1}^{n}\left(\left(x_{i}-\bar{x}\right)\left(y_{i}-\bar{y}\right)\right)}{\sqrt{\sum_{i=1}^{n}\left(x_{i}-\bar{x}\right)^{2} \sum_{i=1}^{n}\left(y_{i}-\bar{y}\right)^{2}}}
$$

where $r$ is the correlation coefficient between annual NDVI and climate indicator; $x_{i}$ and $y_{i}$ are annual NDVI and climate data for year $i$, respectively; and $\bar{x}$ and $\bar{y}$ are the mean of the annual NDVI and climate data over the entire study period, respectively. An $r$ value less (greater) than 0 indicates a negative (positive) correlation. The greater the absolute value of $r$, the higher the correlation between annual NDVI and biotemperature variables. A $\mathrm{P}$ value $<0.05$ for correlation analysis was considered statistically significant.

\subsubsection{Trend Analysis and Mann-Kendall test}

In this study, a linear regression, calculated by the least-squares method, was performed to detect trends in NDVI and climate variables. A positive slope indicates an increasing trend and a negative slope indicates a decreasing trend. In addition, the Mann-Kendall test was adopted to assess the reliability of time series trends (Kendall 1990; Mann 1945). This non-parametric test, which does not require the data to follow a standard distribution pattern and is not affected by sporadic outliers (Sneyers 1990), has been widely used to examine trends in hydrological and environmental data (Luo et al. 2020; Zhao and Wu 2016). In this study, a $P$ value $<0.05$ was considered significant.

\section{Results}

\subsection{Spatial and temporal variation of temperature and NDVI}

Figure 1 illustrates the spatial patterns of trends in annual temperature, annual NDVI, and correlation between annual temperature and annual NDVI over the GLRCA for the period 1982-2014. During the entire study period, annual temperature exhibited an obvious increasing trend and had large spatially heterogeneity. Greater warming $\left(>0.035^{\circ} \mathrm{C} / \mathrm{yr}\right)$ occurred mainly in the west and southeast. Meanwhile, approximately $63.8 \%$ of study area experienced a decreasing trend in annual NDVI. Spatially, the greater 
decrease $\left(<-0.0008 \mathrm{yr}^{-1}\right)$ in annual NDVI was observed mainly in the west, and the greater increase (> $0.0008 \mathrm{yr}^{-1}$ ) was primarily in the east. To investigate the response of vegetation growth to temperature changes, we further analyzed the correlation between annual temperature and annual NDVI based on Pearson's correlation coefficient. From 1982 to 2014, approximately $56.4 \%$ of the study area was subject to a positive correlation between annual temperature and annual NDVI, and a greater positive correlation $(>0.2)$ was observed primarily at high altitudes in the southeast.

\subsection{Spatial and temporal variation of $\mathrm{DT}_{0}, \mathrm{DT}_{5}, \mathrm{DT}_{10}$ and $\mathrm{DT}_{20}$}

To further explore the spatial and temporal variation in temperature, we analyzed the trends in $\mathrm{DT}_{0}, \mathrm{DT}_{5}$, $\mathrm{DT}_{10}$, and $\mathrm{DT}_{20}$ over the GLRCA during 1982-2014. At the regional scale, $\mathrm{DT}_{0}, \mathrm{DT}_{5}, \mathrm{DT}_{10}$, and $\mathrm{DT}_{20}$ exhibited an overall increasing trend at the rate of 0.505 days/yr, 0.503 days/yr, 0.454 days/yr, and 0.398 days/yr, respectively, and all passed the significance test at the 0.01 level (Figure 2). Spatially, the trends in $\mathrm{DT}_{0}, \mathrm{DT}_{5}, \mathrm{DT}_{10}$, and $\mathrm{DT}_{20}$ were obviously heterogeneous over the entire study area (Figure 3 ). The most pronounced increase (>0.6 days/yr) in $\mathrm{DT}_{0}$ was primarily observed in the west and the southeast, accounting for about $28.1 \%$ of the study area. Meanwhile, approximately $31.8 \%$ of the study area experienced a greater increase ( $>0.6$ days/yr) in $\mathrm{DT}_{5}$, and occurred mainly in the central and southeast. For $\mathrm{DT}_{10}$, the greater increase ( $>0.6$ days/yr) was observed mostly in the south, accounting for $22.1 \%$ of the study area. About $23.1 \%$ of the study area showed a larger increase ( $>0.6$ days/yr) in $D_{2}$, occurring mainly in the west and south. In addition, a clearly decreasing trend in $\mathrm{DT}_{20}$ was observed in the northeast, accounting for approximately $10.0 \%$ of the study area.

To further explore the effect of temperature change on vegetation growth, we analyzed the correlation of annual NDVI with $\mathrm{DT}_{0}, \mathrm{DT}_{5}, \mathrm{DT}_{10}$, and $\mathrm{DT}_{20}$ across GLRCA for the period 1982-2014 (Figure 4). Spatially, there was a clear heterogeneity in the correlation between the annual NDVI and the four bio-temperature indicators. From 1982 to 2014, positive correlations between annual NDVI with $\mathrm{DT}_{0}, \mathrm{DT}_{5}$ occurred in $54.8 \%, 46.0 \%$ of the study area, respectively, and greater positive correlations $(>0.30)$ were observed mainly at high elevations in the southeast. Meanwhile, about $66.7 \%$ of study area was subject to a negative correlation between the annual NDVI and the $\mathrm{DT}_{10}$, especially in the central region with a greater negative correlation ( $<-0.30$ ). Furthermore, most of the study area (approximately $88.3 \%$ ) experienced a negative correlation between annual NDVI and $\mathrm{DT}_{20}$, and the greater negative correlation $(<-0.30)$ was widely distributed in the west. Overall, the larger the number of days with higher temperature, the greater the negative impact on vegetation growth.

\subsection{Spatial and temporal variation of SGS, EGS and LGS}

Based on daily mean temperature data in the GLRCA during 1982-2014, we further calculated three biotemperature indicators: SGS, EGS, and LGS. Figure 5 illustrates the interannual trends in SGS, EGS, and LGS at the regional scale in the GLRCA. During the entire study period, SGS exhibited a slight decreasing 
trend with a regional average rate of -0.040 days/yr. Meanwhile, EGS showed a pronounced increasing trend at a rate of 0.460 days/year, and passed the significance test at 0.01 level. Changes in LGS are controlled by changes in SGS and EGS. We further analyzed the interannual trend in LGS and found that LGS across the GLRCA increased at a rate of 0.500 days/yr $(P<0.01)$ at the regional scale.

Figure 6 indicates the spatial distribution of trends in SGS, EGS, and LGS over the GLRCA during the period 1982-2014. Over the past 33 years, most of the study area (about 67.8\%) exhibited a negative trend in SGS. Spatially, the greater advanced SGS ( $<-0.4$ days/yr) was mainly observed in the south, while the delayed SGS was mostly in the north. For trends in EGS, more than $99.0 \%$ of the study area experienced an increasing trend. The larger delays in EGS occurred mainly in the central and southeast. Accompanied by an earlier SGS and a later EGS, LGS showed a pronounced positive trend over $98.1 \%$ of the study area, and a higher extended SGS was observed mainly in the central and south.

Temperature is one of the major drivers of vegetation phenology changes. Therefore, we analyzed the correlations between annual NDVI and three indicators of growing season (SGS, EGS, and LGS) derived from surface air temperature to identify the impact of growing season variability on vegetation dynamics (Figure 7). Over the whole study period, the regions showing a negative correlation between annual NDVI and SGS accounted for about $66.7 \%$ of the study area, and the greater negative correlation $(<-0.2)$ occurred mainly in the north and southeast. Meanwhile, approximately $64.1 \%$ of the study area experienced a negative correlation between annual NDVI and EGS, and a larger negative correlation (< -0.2) was observed mostly in the north. Then, we analyzed the correlation between annual NDVI and LGS, and found that a negative correlation represented approximately $54.7 \%$ of the study area. Spatially, the greater negative correlation $(<-0.2)$ between annual NDVI and LGS was mainly found in the central, and the larger positive correlation $(>0.2)$ was mainly in the southeast.

\section{Discussion}

In this study, we investigated the spatial and temporal variation of bio-temperature indicators (including $\mathrm{DT}_{0}, \mathrm{DT}_{5}, \mathrm{DT}_{10}, \mathrm{DT}_{20}, \mathrm{SGS}, \mathrm{EGS}$, and LGS), and further analyzed the response of vegetation growth to changes in bio-temperature indicators across the GLRCA for the period 1982-2014.

Over the entire study period, GLRCA experienced a significant warming trend, and such climate warming has induced a series of ecological and environmental effects (Liu et al. 2019; Yu et al. 2021). Since the 1970s, nearly half the great lakes in the GLRCA have shrunk, and considerable glaciers are rapidly retreating due to climate warming (Yu et al. 2021). In the present study, a significant decreasing trend in annual NDVI was observed in most of the study area (63.8\%), especially around the Aral Sea, while a significant increasing trend was mainly in the east. This variation in vegetation dynamics was also identified in previous studies (Jiang et al. 2017; Zhang et al. 2018). Meanwhile, numerous studies have suggested that temperature played a major role in the vegetation dynamics across the GLRCA (Jiang et al. 2017; Luo et al. 2020). 
During $1982-2014$, over $56.4 \%$ of the study area experienced a positive correlation between annual temperature and annual NDVI, particularly at high altitudes in the southeast. Generally, at high altitudes, temperature is the dominant climatic factor affecting vegetation growth (Wang et al. 2014; Wang et al. 2021). Thus, the increase in vegetation greenness in the mountainous of the GLRCA could be attributed to climate warming (Jiang et al. 2017; Zhou et al. 2015). However, rapid warming could significantly increase evapotranspiration and lead to soil moisture deficit, which in turn limit vegetation growth (Anderegg et al. 2013; Zhang et al. 2021). This might explain the negative correlation of annual NDVI with annual temperature in the west of the study area.

Climate change manifests itself not only as changes in mean conditions, but also as changes in some key bio-temperature thresholds (Zhao and Wu 2016). Key bio-temperature are closely related to the growth of vegetation, and slight changes could produce substantial effects on the structure and function of ecosystems (Yang et al. 2019; Yin et al. 2019). Therefore, we further analyzed the spatial and temporal trends in $\mathrm{DT}_{0}, \mathrm{DT}_{5}, \mathrm{DT}_{10}$, and $\mathrm{DT}_{20}$. Overall, four indicators showed a pronounced increasing trend, which is the consequence of increased temperature in the GLRCA (Feng et al. 2018). Spatially, this increase has significant variability, which should be strongly associated with the spatial and temporal heterogeneity in surface characteristics, such as topography and urbanization (Toelle and Churiulin 2021). Moreover, a clearly decreasing trend in $\mathrm{DT}_{20}$ was observed in the northeast, and Figure 1 (a) reveals that the annual mean temperature in the region also insignificantly increased during 1982-2014. Previous studies found that increased precipitation and vegetation greening could induce a cooling effect on regional temperatures (Barbero et al. 2018; Yuan et al. 2017). Therefore, the increase in precipitation and NDVI over the northeastern GLRCA should contribute to the decrease in DT 20 (Jiang et al. 2017).

For the period 1982-2014, the correlations of annual NDVI with $\mathrm{DT}_{0}, \mathrm{DT}_{5}, \mathrm{DT}_{10}$, and $\mathrm{DT}_{20}$ showed obviously spatially heterogeneous. It implied that the response of vegetation dynamics to temperature drivers was highly variable due to different vegetation characteristics and environmental conditions (Li et al. 2021b; Luo et al. 2020). A slight increase in temperature would exert a positive impact on regional vegetation growth by reducing frost days and extending the growing season (Wu et al. 2021; Zhao et al. 2021). At the same time, a significant positive correlation between annual NDVI and temperature indicators was observed at high elevations in the southeast because cold temperature is a serious constraint to vegetation growth in the region (Jiang et al. 2017). However, most of the regions in GLRCA showed that the negative correlation between $\mathrm{DT}_{0}, \mathrm{DT}_{5}, \mathrm{DT}_{10}, \mathrm{DT}_{20}$ with annual NDVI increased with increasing bio-temperature thresholds, which may be due to increased temperature intensifying precipitation limitation for dryland vegetation growth (Wu et al. 2019; Zhang et al. 2016). Especially, more than $88.3 \%$ of the study area showed a negative correlation between annual NDVI and $\mathrm{DT}_{20}$. In general, $\mathrm{DT}_{20}$ occurred mainly in summer, and high temperatures could further increase ecosystem drought. Recently, the negative effects of high temperatures on ecosystems have been widely reported in many regions, especially in arid and semi-arid areas (Baumbach et al. 2017; Li et al. 2021b). Under high temperature stress, vegetation photosynthesis is weakened or even stalled, while respiration is enhanced, thus leading to a decrease in productivity (Salvucci and Crafts-Brandner 2004; von Buttlar et al. 2018). 
Vegetation phenology, including SGS, EGS, and LGS, is a sensitive signal indicating the response of vegetation dynamics to climate change (Richardson et al. 2012; Wu et al. 2021). Plenty of remote sensing data and ground observation data demonstrated that spring phenology has advanced and fall phenology has delayed owing to global warming (Dong et al. 2012; Sun et al. 2020; Wu et al. 2021). In this study, LGS presented a significant positive trend at a rate 0.500 days/yr for the regional scale, and delayed EGS ( 0.460 days/year) contributed greater relative to advanced SGS ( -0.040 days/yr). This result is consistent with other studies around the globe (Dong et al. 2012; Sun et al. 2020). Spatially, a pronounced delay in SGS was observed in the north. In fact, spring cooling has been noted in some regions of the Northern Hemisphere over the last decades (Sun et al. 2019; Wang et al. 2011). Such a spring cooling could possibly result in delayed SGS in the GLRCA. In addition, the spatial pattern of LGS was similar to that of $\mathrm{DT}_{5}$ because the growing season in this study was defined based on $5^{\circ} \mathrm{C}$ and $\mathrm{DT}_{5}$ in a year occurred mostly within the growing season.

Environmental changes are inconsistent with the vegetation response, which may lead to different trends in growing season derived from surface air temperature and growing season based on actual vegetation phenology (Sun et al. 2020; Wu et al. 2021). Therefore, we further analyzed the correlations between annual NDVI with SGS, EGS, and LGS. Generally, prolonged LGS controlled by advanced SGS and delayed EGS can increase the time of material accumulation, thereby enhancing vegetation productivity (Piao et al. 2007; Richardson et al. 2010). Meanwhile, a pronounced positive correlation between annual NDVI and LGS was observed at high elevations in the southeast. Furthermore, our study found that annual NDVI was negatively correlated with LGS in some regions of the GLRCA, especially in the north. In dryland ecosystems, precipitation is the major driver of vegetation greening, and increased evapotranspiration controlled by climate warming would lead to drought and exacerbate precipitation limitation (Ma et al. 2015). In addition, the increase in temperature might accelerate the growth of vegetation and thus lead to a shortening of the vegetation growth cycle, particularly for herbaceous plants (Sherry et al. 2007; Wu et al. 2021). Hence, these could explain the negative effect of extended LGS on vegetation growth across the GLRCA.

\section{Conclusions}

This study analyzed the temporal and spatial characteristics of bio-temperature indicators ( $\mathrm{DT}_{0}, \mathrm{DT}_{5}$, $\mathrm{DT}_{10}, \mathrm{DT}_{20}, \mathrm{SGS}, \mathrm{EGS}$, and LGS) in the GLRCA based on surface air temperature data during 1982-2014, and examined the response of vegetation dynamics to climate change. The major findings are as follows.

(1) With climate warming, $\mathrm{DT}_{0}, \mathrm{DT}_{5}, \mathrm{DT}_{10}$, and $\mathrm{DT}_{20}$ all showed a pronounced increasing trend at the regional scale. Spatially, there was significant heterogeneity in the four indicators, particularly an obvious decrease in $\mathrm{DT}_{20}$ was observed in the northeast.

(2) Most of the study area showed that the negative correlation between $\mathrm{DT}_{0}, \mathrm{DT}_{5}, \mathrm{DT}_{10}, \mathrm{DT}_{20}$ with annual NDVI increased with increasing bio-temperature thresholds. Especially, more than $88.3 \%$ of the study area experienced a negative correlation between annual NDVI and $\mathrm{DT}_{20}$. 
(3) During the entire study period, SGS exhibited insignificantly advanced trend, and EGS experienced a significantly delayed trend. Therefore, the overall extending trend in LGS was mainly attributed to the delayed EGS.

(4) About $54.7 \%$ of the study area showed a negative correlation between annual NDVI and LGS due to precipitation limitation exacerbated by climate warming, especially in the north, indicating a negative effect of climate warming on dryland vegetation growth.

\section{Declarations}

\section{Funding}

This study was supported by the Strategic Priority Research Program of Chinese Academy of Sciences (XDA20020202).

\section{Competing Interests}

The authors have no relevant financial or non-financial interests to disclose.

\section{Author Contributions}

Xuan Gao and Lei Liu analyzed the data and wrote the manuscript. Dongsheng Zhao provided guidance and revised the manuscript.

\section{Data Availability}

Meteorological data supporting this research are openly available at https://disc.gsfc.nasa.gov/.

\section{References}

1. Anderegg WRL, Kane JM, Anderegg LDL (2013) Consequences of widespread tree Mortality triggered by drought and temperature stress. Nat Clim Chang 3(1):30-36.

https://doi.org/10.1038/nclimate1635

2. Ballantyne AP, Alden CB, Miller JB, Tans PP, White JWC (2012) Increase in observed net carbon dioxide uptake by land and oceans during the past 50 years. Nature 488(7409):70-+. https://doi.org/10.1038/nature11299

3. Barbero R, Westra S, Lenderink G, Fowler HJ (2018) Temperature-extreme precipitation scaling: a twoway causality? Int J Climatol 38:E1274-E1279. https://doi.org/10.1002/joc.5370

4. Baumbach L, Siegmund JF, Mittermeier M, Donner RV (2017) Impacts of temperature extremes on European vegetation during the growing season. Biogeosciences 14(21):4891-4903. https://doi.org/10.5194/bg-14-4891-2017 
5. Bohovic R, Dobrovolny P, Klein D (2016) The Spatial and Temporal Dynamics of Remotely-sensed Vegetation Phenology in Central Asia in the 1982-2011 Period. Eur J Remote Sens 49:279-299. https://doi.org/10.5721/EuJRS20164916

6. Bolch T, Yao T, Kang S, Buchroithner MF, Scherer D et al (2010) A glacier inventory for the western Nyainqentanglha Range and the Nam Co Basin, Tibet, and glacier changes 1976-2009. Cryosphere 4(3):419-433. https:// doi.org/10.5194/tc-4-419-2010

7. Cheng W, Li Z, Yan L (2021) Uniforming spring phenology under non-uniform climate warming across latitude in China. Sci Total Environ 762(2):143177-143177. https://doi.org/10.1016/j.scitotenv.2020.143177

8. Cornes RC, van der Schrier G, Squintu AA (2019) A reappraisal of the thermal growing season length across Europe. Int J Climatol 39(3):1787-1795. https://doi.org/10.1002/joc.5913

9. Dong MY, Jiang Y, Zheng CT, Zhang DY (2012) Trends in the thermal growing season throughout the Tibetan Plateau during 1960-2009. Agric For Meteorol 166:201-206.

https://doi.org/10.1016/j.agrformet.2012.07.013

10. Feng R, Yu RD, Zheng HW, Gan M (2018) Spatial and temporal variations in extreme temperature in Central Asia. Int J Climatol 38:E388-E400. https://doi.org/10.1002/joc.5379

11. Franzke CLE (2015) Local trend disparities of European minimum and maximum temperature extremes. Geophysical Research Letters 42(15):6479-6484. https://doi.org/10.1002/2015gl065011

12. Fu B, Forsius M, Liu J (2013) Ecosystem services: climate change and policy impacts Editorial overview. Current Opinion in Environmental Sustainability 5(1):1-3.

https://doi.org/10.1016/j.cosust.2013.02.003

13. Goward SN (1989) Satellite Bioclimatology. J Climate 2(7):710-720. https://doi.org/10.1175/15200442(1989)002<0710:SB>2.0.CO;2

14. Holst R, Yu XH, Grun C (2013) Climate Change, Risk and Grain Yields in China. J Integr Agric 12(7):1279-1291. https://doi.org/10.1016/s2095-3119(13)60435-9

15. Hu ZY, Zhang C, Hu Q, Tian HQ (2014) Temperature Changes in Central Asia from 1979 to 2011 Based on Multiple Datasets. J Climate 27(3):1143-1167. https://doi.org/10.1175/jcli-d-13-00064.1

16. Huang B (1958) Draft of the comprehensive physical geographical regionalization of China. Acta Geographica Sinica(04):348-365. https://doi.org/10.11821/xb195804002

17. IPCC (2021) Summary for Policymakers. In: Climate Change 2021: The Physical Science Basis. Contribution of Working Group I to the Sixth Assessment Report of the Intergovernmental Panel on Climate Change [Masson-Delmotte, V., P. Zhai, A. Pirani, S. L. Connors, C. Péan, S. Berger, N. Caud, Y. Chen, L. Goldfarb, M. I. Gomis, M. Huang, K. Leitzell, E. Lonnoy, J.B.R. Matthews, T. K. Maycock, T. Waterfield, O. Yelekçi, R. Yu and B. Zhou (eds.)]. Cambridge University Press.

18. Ji L, Senay GB, Verdin JP (2015) Evaluation of the Global Land Data Assimilation System (GLDAS) Air Temperature Data Products. J Hydrometeorol 16(6):2463-2480. https://doi.org/10.1175/jhm-d14-0230.1 
19. Jiang LL, Jiapaer G, Bao AM, Guo H, Ndayisaba F (2017) Vegetation dynamics and responses to climate change and human activities in Central Asia. Sci Total Environ 599:967-980. https://doi.org/10.1016/j.scitotenv.2017.05.012

20. Kendall MG (1990) Rank Correlation Methods. Br J Psychol 25(1):86-91. https://doi.org/10.2307/2333282

21. Larcher W, Biederman-Thorson MA (1980) Physiological Plant Ecology. Springer, Berlin

22. Li CF, Zhang C, Luo GP, Chen X, Maisupova B et al (2015a) Carbon stock and its responses to climate change in Central Asia. Glob Change Biol 21(5):1951-1967. https://doi.org/10.1111/gcb.12846

23. Li HW, Li YP, Huang GH, Sun J (2021a) Quantifying effects of compound dry-hot extremes on vegetation in Xinjiang (China) using a vine-copula conditional probability model. Agric For Meteorol 311. https://doi.org/10.1016/j.agrformet.2021.108658

24. Li S, Wei FL, Wang Z, Shen JS, Liang Z et al (2021b) Spatial Heterogeneity and Complexity of the Impact of Extreme Climate on Vegetation in China. Sustainability 13(10):17. https://doi.org/10.3390/su13105748

25. Li Z, Chen YN, Li WH, Deng HJ, Fang GH (2015b) Potential impacts of climate change on vegetation dynamics in Central Asia. J Geophys Res-Atmos 120(24):12345-12356. https://doi.org/10.1002/2015jd023618

26. Lioubimtseva E, Henebry GM (2009) Climate and environmental change in arid Central Asia: Impacts, vulnerability, and adaptations. J Arid Environ 73(11):963-977.

https://doi.org/10.1016/j.jaridenv.2009.04.022

27. Liu HJ, Chen YN, Ye ZX, Li YP, Zhang QF (2019) Recent Lake Area Changes in Central Asia. Sci Rep 9:11. https://doi.org/10.1038/s41598-019-52396-y

28. Liu Q, Piao SL, Janssens IA, Fu YS, Peng SS et al (2018) Extension of the growing season increases vegetation exposure to frost. Nature Communications 9(1):426. https://doi.org/10.1038/s41467-01702690-y

29. Liu YR, Li YP, Yang X, Huang GH, Li YF (2021) Development of an integrated multivariate trendfrequency analysis method: Spatial-temporal characteristics of climate extremes under global warming for Central Asia. Environ Res 195:14. https://doi.org/10.1016/j.envres.2021.110859

30. Luo M, Sa CL, Meng FH, Duan YC, Liu T et al (2020) Assessing extreme climatic changes on a monthly scale and their implications for vegetation in Central Asia. J Clean Prod 271:11. https://doi.org/10.1016/j.jclepro.2020.122396

31. Ma XL, Huete A, Moran S, Ponce-Campos G, Eamus D (2015) Abrupt shifts in phenology and vegetation productivity under climate extremes. J Geophys Res-Biogeosci 120(10):2036-2052. https://doi.org/10.1002/2015jg003144

32. Mann HB (1945) NONPARAMETRIC TESTS AGAINST TREND. Econometrica 13(3):245-259. https://doi.org/10.2307/1907187

33. Perkins SE, Alexander LV, Nairn JR (2012) Increasing frequency, intensity and duration of observed global heatwaves and warm spells. Geophys Res Lett 39:5. https://doi.org/10.1029/2012gl053361 
34. Piao SL, Friedlingstein P, Ciais P, Viovy N, Demarty J (2007) Growing season extension and its impact on terrestrial carbon cycle in the Northern Hemisphere over the past 2 decades. Glob Biogeochem Cycle 21(3):11. https://doi.org/10.1029/2006gb002888

35. Piao SL, Wang XH, Ciais P, Zhu B, Wang T et al (2011) Changes in satellite-derived vegetation growth trend in temperate and boreal Eurasia from 1982 to 2006. Glob Change Biol 17(10):3228-3239. https://doi.org/10.1111/j.1365-2486.2011.02419.x

36. Prentice IC, Cramer W, Harrison SP, Leemans R, Monserud RA et al (1992) A global biome model based on plant physiology and dominance, soil properties and climate. J Biogeogr 19(2):117-134. https://doi.org/10.2307/2845499

37. Qiu B, Lu Q (1980) A tentative regionalization of agroclimate of China. Acta Geographica Sinica.

38. Richardson AD, Anderson RS, Arain MA, Barr AG, Bohrer G et al (2012) Terrestrial biosphere models need better representation of vegetation phenology: results from the North American Carbon Program Site Synthesis. Glob Change Biol 18(2):566-584. https://doi.org/10.1111/j.13652486.2011.02562.x

39. Richardson AD, Black TA, Ciais P, Delbart N, Friedl MA et al (2010) Influence of spring and autumn phenological transitions on forest ecosystem productivity. Philos Trans R Soc B-Biol Sci 365(1555):3227-3246. https://doi.org/10.1098/rstb.2010.0102

40. Ruml M, Gregoric E, Vujadinovic M, Radovanovic S, Matovic G et al (2017) Observed changes of temperature extremes in Serbia over the period 1961-2010. Atmos Res 183:26-41. https://doi.org/10.1016/j.atmosres.2016.08.013

41. Salvucci ME, Crafts-Brandner SJ (2004) Inhibition of photosynthesis by heat stress: the activation state of Rubisco as a limiting factor in photosynthesis. Physiol Plant 120(2):179-186. https://doi.org/10.1111/j.0031-9317.2004.0173.x

42. Sherry RA, Zhou XH, Gu SL, Arnone JA, Schimel DS et al (2007) Divergence of reproductive phenology under climate warming. Proc Natl Acad Sci U S A 104(1):198-202. https://doi.org/10.1073/pnas.0605642104

43. Sillmann J, Kharin VV, Zhang X, Zwiers FW, Bronaugh D (2013) Climate extremes indices in the CMIP5 multimodel ensemble: Part 1. Model evaluation in the present climate. J Geophys Res-Atmos 118(4):1716-1733. https://doi.org/10.1002/jgrd.50203

44. Sitch S, Friedlingstein P, Gruber N, Jones SD, Murray-Tortarolo G et al (2015) Recent trends and drivers of regional sources and sinks of carbon dioxide. Biogeosciences 12(3):653-679. https://doi.org/10.5194/bg-12-653-2015

45. Sneyers R (1990) On the Statistical Analysis of Series of Observations. J Biol Chem 258(22):136804. https://doi.org/10.1021/ja00723a061

46. Sun C, Kucharski F, Li JP, Wang KC, Kang IS et al (2019) Spring Aleutian Low Weakening and Surface Cooling Trend in Northwest North America During Recent Decades. J Geophys Res-Atmos 124(22):12078-12092. https://doi.org/10.1029/2019jd031405 
47. Sun QL, Li BL, Zhou GY, Jiang YH, Yuan YC (2020) Delayed autumn leaf senescence date prolongs the growing season length of herbaceous plants on the Qinghai-Tibetan Plateau. Agric For Meteorol 284:11. https://doi.org/10.1016/j.agrformet.2019.107896

48. Toelle MH, Churiulin E (2021) Sensitivity of Convection-Permitting Regional Climate Simulations to Changes in Land Cover Input Data: Role of Land Surface Characteristics for Temperature and Climate Extremes. Frontiers in Earth Science 9. https://doi.org/10.3389/feart.2021.722244

49. Tong SQ, Li XQ, Zhang JQ, Bao YH, Bao YB et al (2019) Spatial and temporal variability in extreme temperature and precipitation events in Inner Mongolia (China) during 1960-2017. Sci Total Environ 649:75-89. https://doi.org/10.1016/j.scitotenv.2018.08.262

50. von Buttlar J, Zscheischler J, Rammig A, Sippel S, Reichstein M et al (2018) Impacts of droughts and extreme-temperature events on gross primary production and ecosystem respiration: a systematic assessment across ecosystems and climate zones. Biogeosciences 15(5):1293-1318. https://doi.org/10.5194/bg-15-1293-2018

51. Wang HL, Tetzlaff D, Buttle J, Carey SK, Laudon H et al (2019) Climate-phenology-hydrology interactions in northern high latitudes: Assessing the value of remote sensing data in catchment ecohydrological studies. Sci Total Environ 656:19-28.

https://doi.org/10.1016/j.scitotenv.2018.11.361

52. Wang QX, Fan XH, Wang MB (2014) Recent warming amplification over high elevation regions across the globe. Clim Dyn 43(1-2):87-101. https://doi.org/10.1007/s00382-013-1889-3

53. Wang TH, Yang DW, Yang YT, Piao SL, Li X et al (2020) Permafrost thawing puts the frozen carbon at risk over the Tibetan Plateau. Sci Adv 6(19):8. https://doi.org/10.1126/sciadv.aaz3513

54. Wang XH, Piao SL, Ciais P, Li JS, Friedlingstein P et al (2011) Spring temperature change and its implication in the change of vegetation growth in North America from 1982 to 2006 . Proc Natl Acad Sci U S A 108(4):1240-1245. https://doi.org/10.1073/pnas.1014425108

55. Wang ZQ, Cui GL, Liu X, Zheng K, Lu ZY et al (2021) Greening of the Qinghai-Tibet Plateau and Its Response to Climate Variations along Elevation Gradients. Remote Sens 13(18):20. https://doi.org/10.3390/rs13183712

56. Wei H, Zhao X, Liang S, Zhou T, Wu D et al (2018) Effects of Warming Hiatuses on Vegetation Growth in the Northern Hemisphere. Remote Sens 10(5):683. https://doi.org/10.3390/rs10050683

57. Wu LZ, Ma XF, Dou X, Zhu JT, Zhao CY (2021) Impacts of climate change on vegetation phenology and net primary productivity in arid Central Asia. Sci Total Environ 796:15. https://doi.org/10.1016/j.scitotenv.2021.149055

58. Wu XC, Guo WC, Liu HY, Li XY, Peng CH et al (2019) Exposures to temperature beyond threshold disproportionately reduce vegetation growth in the northern hemisphere. Natl Sci Rev 6(4):786-795. https://doi.org/10.1093/nsr/nwy158

59. Xiao WW, Wang B, Liu DL, Feng PY (2020) Projecting Changes in Temperature Extremes in the Han River Basin of China Using Downscaled CMIP5 Multi-Model Ensembles. Atmosphere 11(4):21. https://doi.org/10.3390/atmos11040424 
60. Xu L, Myneni RB, Chapin FS, Callaghan TV, Pinzon JE et al (2013) Temperature and vegetation seasonality diminishment over northern lands. Nat Clim Chang 3(6):581-586. https://doi.org/10.1038/nclimate1836

61. Yang Y, Zhao D, Chen $\mathrm{H}$ (2019) Variability of bio-climatology indicators in the Southwest China under climate warming during 1961-2015. Int J Biometeorol 63(1):107-119. https://doi.org/10.1007/s00484-018-1640-1

62. Yao JQ, Chen YN, Zhao Y, Mao WY, Xu XB et al (2018) Response of vegetation NDVI to climatic extremes in the arid region of Central Asia: a case study in Xinjiang, China. Theor Appl Climatol 131(3-4):1503-1515. https://doi.org/10.1007/s00704-017-2058-0

63. Yao T, Chen F, Cui P, Ma Y, BaiqingXu (2017) From Tibetan Plateau to Third Pole and Pan-Third Pole. Bull Chin Acad Sci 32(9):924-931. https://doi.org/10.16418/j.issn.1000-3045.2017.09.001

64. Yin YH, Deng HY, Wu SH (2017) A new method for generating the thermal growing degree-days and season in China during the last century. Int J Climatol 37(3):1131-1140. https://doi.org/10.1002/joc.4781

65. Yin YH, Deng HY, Wu SH (2019) Spatial-temporal variations in the thermal growing degree-days and season under climate warming in China during 1960-2011. Int J Biometeorol 63(5):649-658. https://doi.org/10.1007/s00484-017-1417-y

66. Yu Y, Chen X, Malik I, Wistuba M, Cao YG et al (2021) Spatiotemporal changes in water, land use, and ecosystem services in Central Asia considering climate changes and human activities. J Arid Land 13(9):881-890. https://doi.org/10.1007/s40333-021-0084-3

67. Yuan X, Wang W, Cui J, Meng F, Kurban A et al (2017) Vegetation changes and land surface feedbacks drive shifts in local temperatures over Central Asia. Sci Rep 7:3287. https://doi.org/10.1038/s41598-017-03432-2

68. Yuan Y, Bao A, Liu T, Zheng G, Jiang $L$ et al (2021) Assessing vegetation stability to climate variability in Central Asia. J Environ Manage 298. https://doi.org/10.1016/j.jenvman.2021.113330

69. Zhang C, Lu DS, Chen X, Zhang YM, Maisupova B et al (2016) The spatiotemporal patterns of vegetation coverage and biomass of the temperate deserts in Central Asia and their relationships with climate controls. Remote Sens Environ 175:271-281. https://doi.org/10.1016/j.rse.2016.01.002

70. Zhang GL, Biradar CM, Xiao XM, Dong JW, Zhou YT et al (2018) Exacerbated grassland degradation and desertification in Central Asia during 2000-2014. Ecol Appl 28(2):442-456.

https://doi.org/10.1002/eap.1660

71. Zhang M, Chen YN, Shen YJ, Li BF (2019) Tracking climate change in Central Asia through temperature and precipitation extremes. J Geogr Sci 29(1):3-28. https://doi.org/10.1007/s11442019-1581-6

72. Zhang W, Li Y, Wu X, Chen Y, Chen A et al (2021) Divergent Response of Vegetation Growth to Soil Water Availability in Dry and Wet Periods Over Central Asia. J Geophys Res-Biogeosci 126(6). https://doi.org/10.1029/2020jg005912 
73. Zhao D, Gao X, Yang Y (2021) Trends of freezing period and its main cause on the Qinghai-Tibetan Plateau from 1961 to 2018. Theor Appl Climatol 146(3-4):1355-1366.

https://doi.org/10.1007/s00704-021-03798-4

74. Zhao DS, Wu SH (2016) Spatial and temporal variability of key bio-temperature indicators on the Qinghai-Tibetan Plateau for the period 1961-2013. Int J Climatol 36(4):2083-2092. https://doi.org/10.1002/joc.4482

75. Zheng GH, Yang YT, Yang DW, Dafflon B, Yi YH et al (2020) Remote sensing spatiotemporal patterns of frozen soil and the environmental controls over the Tibetan Plateau during 2002-2016. Remote Sens Environ 247:19. https://doi.org/10.1016/j.rse.2020.111927

76. Zhong L, Su ZB, Ma YM, Salama MS, Sobrino JA (2011) Accelerated Changes of Environmental Conditions on the Tibetan Plateau Caused by Climate Change. J Climate 24(24):6540-6550. https://doi.org/10.1175/jcli-d-10-05000.1

77. Zhou Y, Zhang L, Fensholt R, Wang K, Vitkovskaya I et al (2015) Climate Contributions to Vegetation Variations in Central Asian Drylands: Pre- and Post-USSR Collapse. Remote Sens 7(3):2449-2470. https://doi.org/10.3390/rs70302449

\section{Figures}

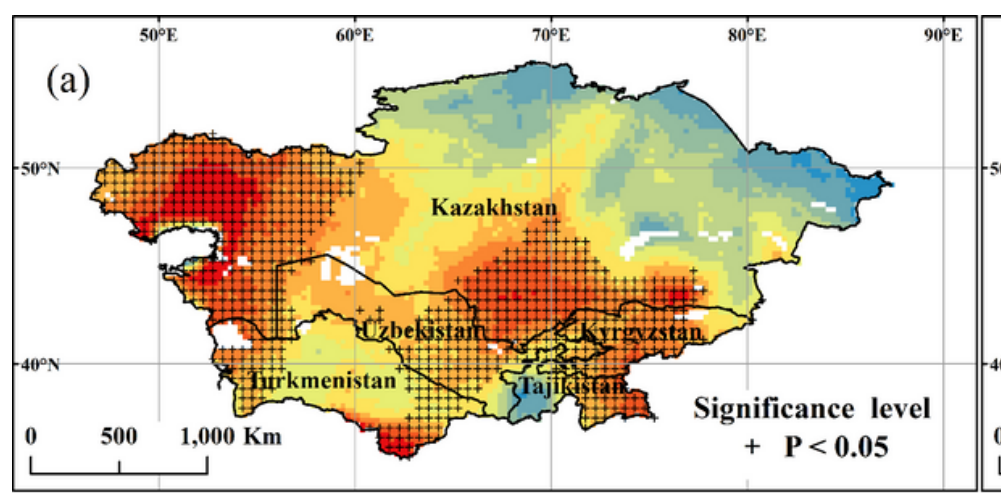

Temperature $\left({ }^{\circ} \mathrm{C} / \mathbf{y r}\right)$

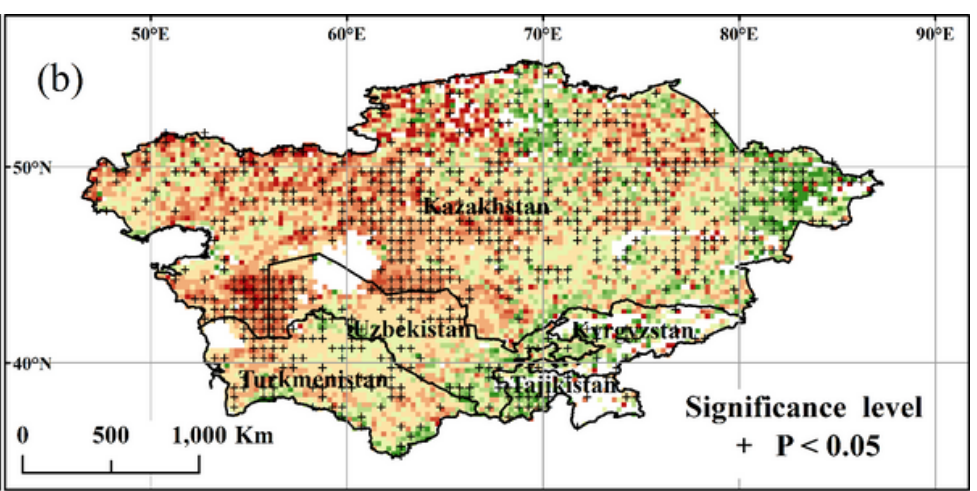

NDVI (1/yr)

\section{$\begin{array}{lllllllll}0.005 & 0.010 & 0.015 & 0.020 & 0.025 & 0.030 & 0.035 & 0.040 & 0.045\end{array}$}

$-0.0016-0.0012-0.0008-0.0004$

$\begin{array}{llll}0.0004 & 0.0008 & 0.0012 & 0.0016\end{array}$
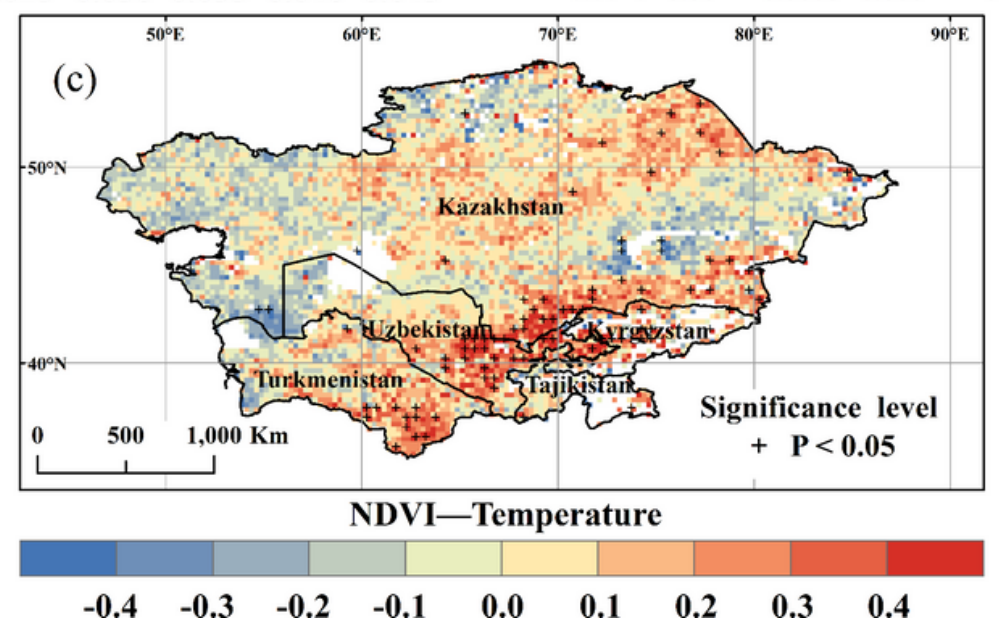

Figure 1 
Spatial distribution of trends in (a) annual temperature, (b) annual NDVI, and (c) correlation between annual temperature and annual NDVI over the GLRCA during 1982-2014.
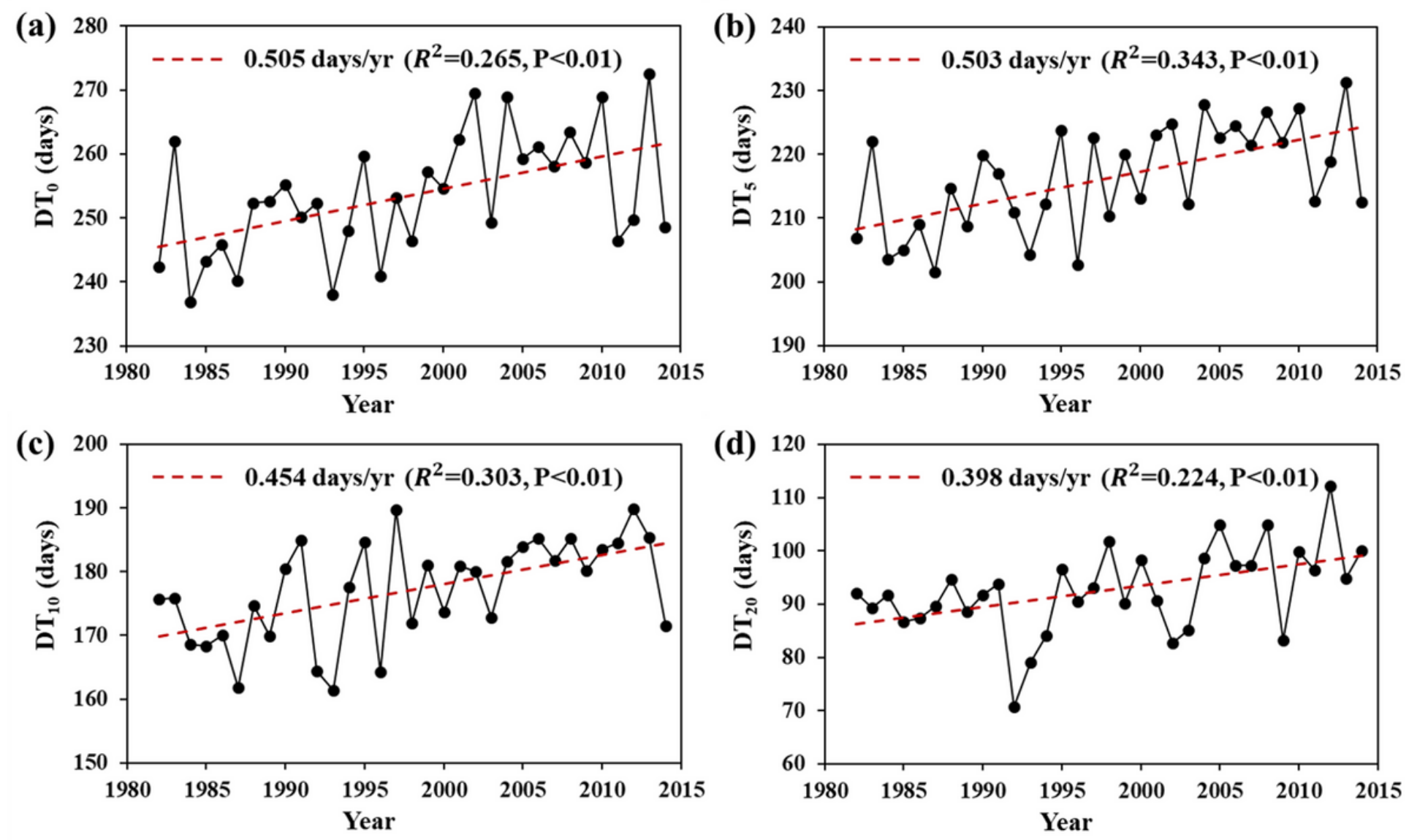

Figure 2

Interannual variations in (a) $\mathrm{DT}_{0}$, (b) $\mathrm{DT}_{5},(\mathrm{c}) \mathrm{DT}_{10}$, and (d) $\mathrm{DT}_{20}$ at a regional scale in the GLRCA during the period 1982-2014. 

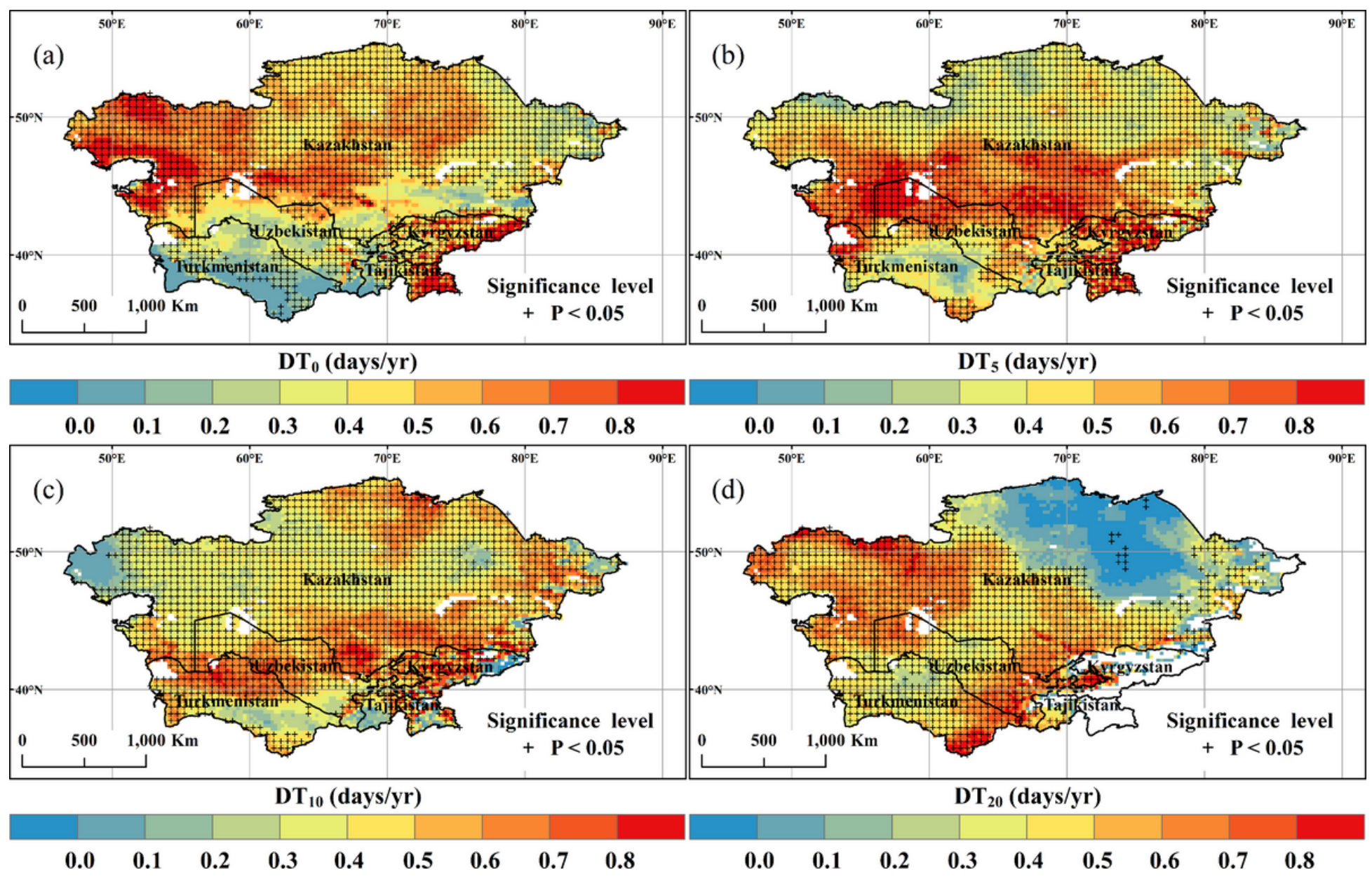

Figure 3

Spatial distribution of trends in (a) $\mathrm{DT}_{0}$, (b) $\mathrm{DT}_{5},(\mathrm{c}) \mathrm{DT}_{10}$, and (d) $\mathrm{DT}_{20}$ during the period 1982-2014. 

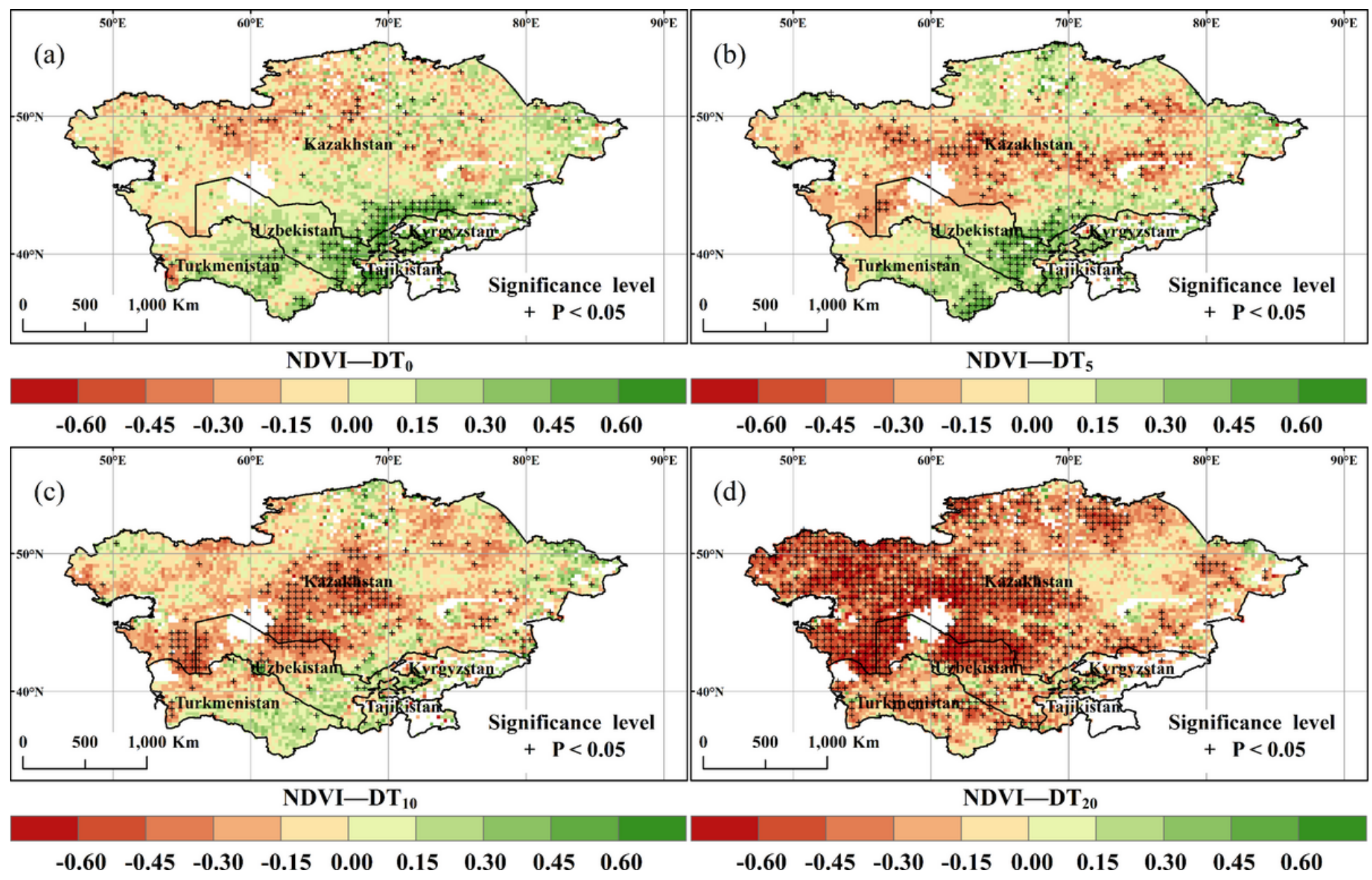

Figure 4

Spatial distribution of correlations between annual NDVI and (a) DT 0 , (b) DT 5 , (c) DT 10 , and (d) DT 20 for the period 1982-2014. 

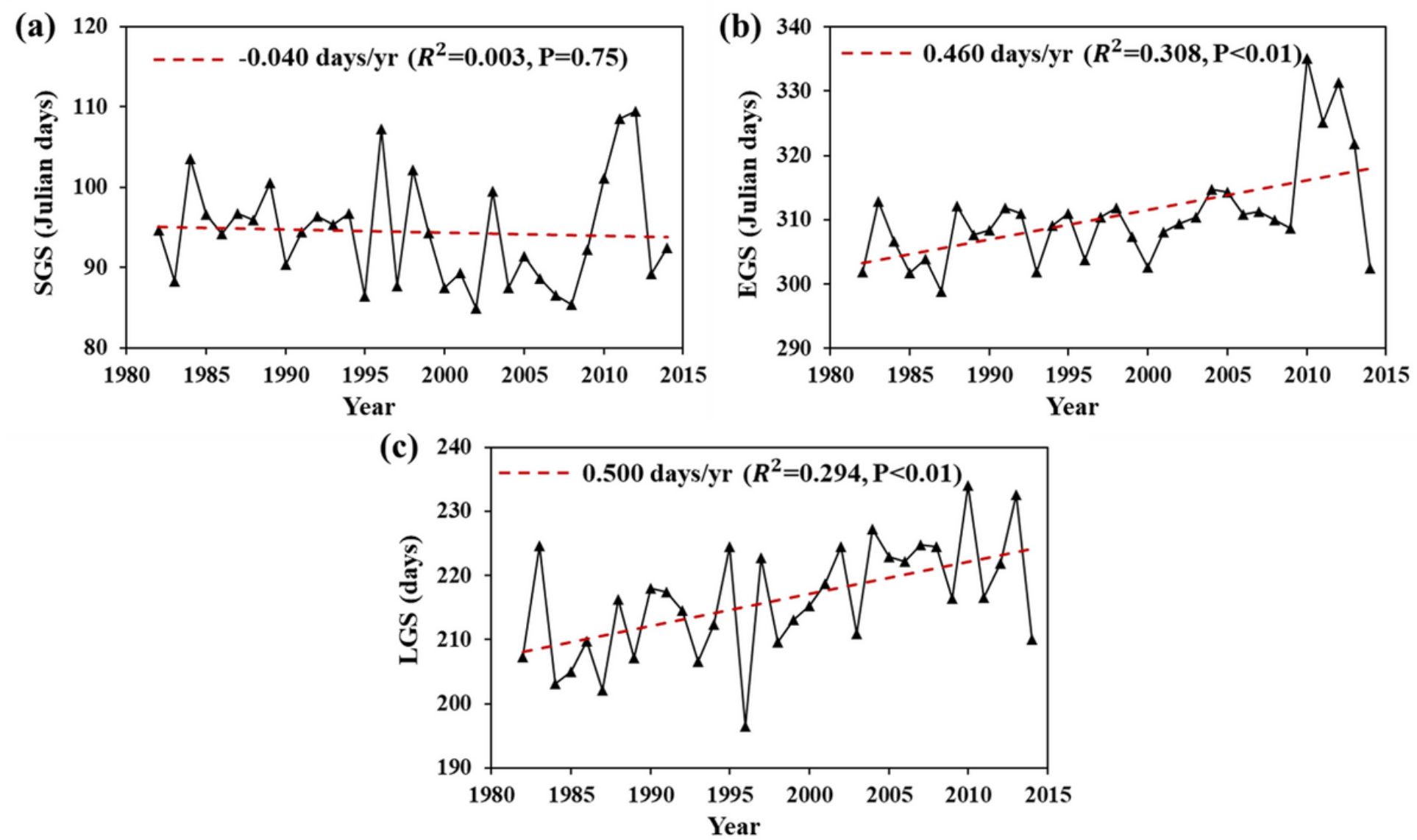

\section{Figure 5}

Interannual variations in (a) SGS, (b) EGS, and (c) LGS at a regional scale in the GLRCA during the period 1982-2014. 

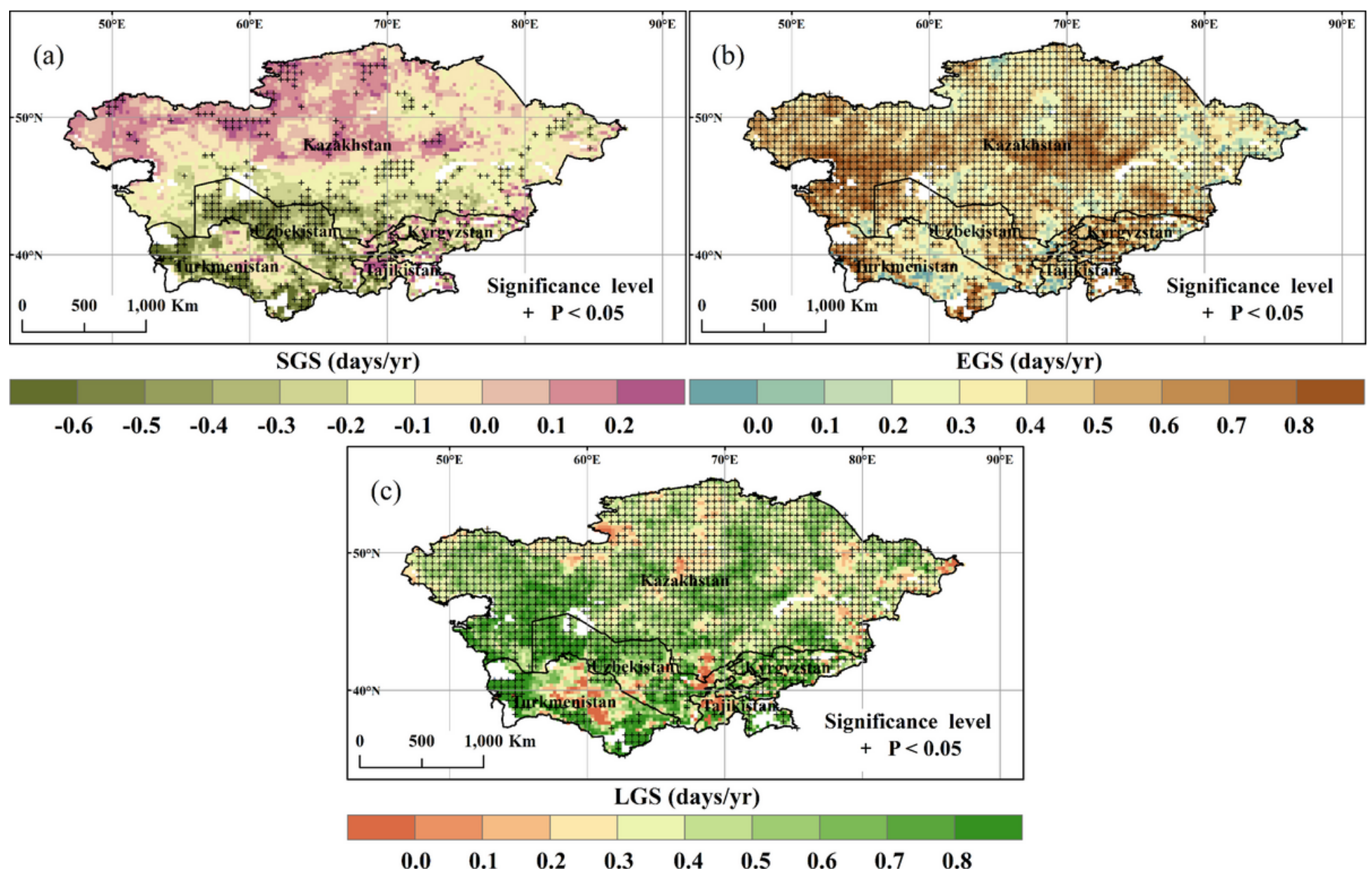

Figure 6

Spatial distribution of trends in (a) SGS, (b) EGS, and (c) LGS for the period 1982-2014. 


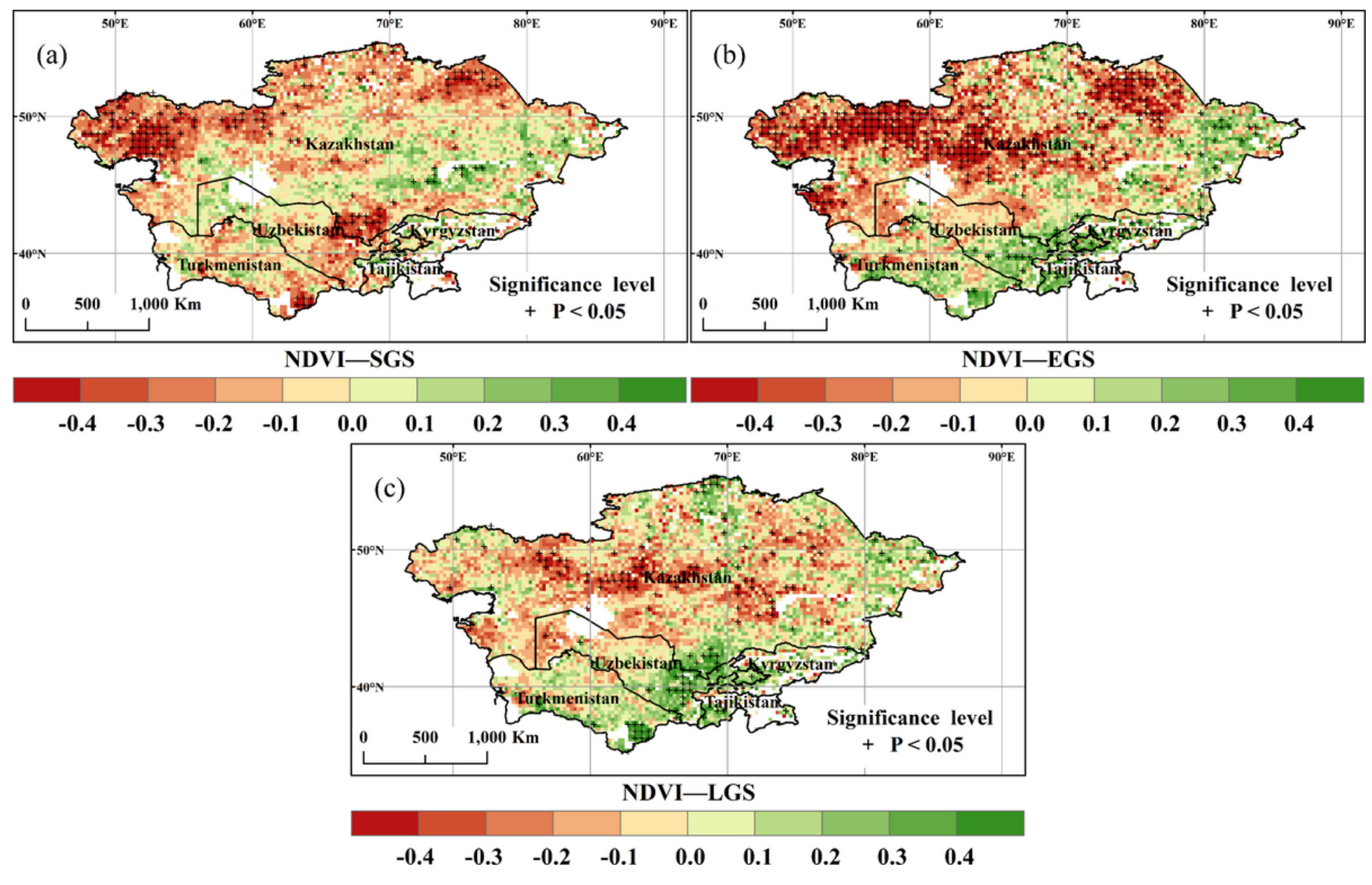

Figure 7

Spatial distribution of correlations between annual NDVI and (a) SGS, (b) EGS, and (c) LGS during 19822014. 